\title{
Concordance between different measures of biodiversity in Indian Ocean macroalgae
}

\author{
A. R. G. Price ${ }^{1, *}$, L. P. A. Vincent ${ }^{1}$, A. J. Venkatachalam ${ }^{1}$, J. J. Bolton ${ }^{2}$, P. W. Basson ${ }^{3}$ \\ ${ }^{1}$ Ecology and Epidemiology Group, Department of Biological Sciences, University of Warwick, Coventry CV4 7AL, UK \\ ${ }^{2}$ Botany Department, University of Cape Town, Rondebosch 7701, South Africa \\ ${ }^{3}$ School of Biological Sciences, University of Bristol, Woodland Road, Clifton, Bristol, BS8 1UG, UK
}

\begin{abstract}
We examine relationships between species richness $(S)$, rarity $(R)$ and average taxonomic distinctness $\left(\Delta^{+}\right)$from analysis of a comprehensive dataset for benthic marine algae (including Cyanophyta). This comprises 2894 species from 66 sites across the Indian Ocean. Ranked values for the sites, determined according to the 3 metrics, show significant positive correlation ( $p \leq 0.01)$; Mauritius, India and Aldabra emerge as biodiversity 'hotspots', while Indonesia (Nias Island), Maldives (Male Atoll) and the Gulf of Aden are 'coldspots'. Concordance between metrics was unexpected, given their disparity in robustness to sampling rigour and particularly since $\Delta^{+}$is conceptually unrelated to $S$ and $R$. Lack of significant latitudinal correlations was also evident except for $\Delta^{+}$, which increased towards temperate waters in the southern hemisphere. This contrasts with the variable patterns observed with longitude, for which significant correlations (negative, i.e. towards the west) were prevalent only for $S$ (algae overall and separate categories except Phaeophyta), evident for $R$ (Cyanophyta only) and absent for $\Delta^{+}$. Hence, use of one floral category as a surrogate for biodiversity in another is not guaranteed. Aquatic biodiversity patterns are complex, in accordance with recent findings derived mainly from faunal datasets. Relationships between different metrics can depend on both the group(s) selected and the environmental or geographical factor(s) examined. Our study is based on analysis of extensive but low resolution (presence/absence) data (Silva et al. 1996) collected from sites of variable size that were not sampled evenly. We address these constraints, but acknowledge the possibility that some patterns may prove to be artefacts, pending analysis of data from recent and ongoing studies. However, we do not expect this to significantly affect our overall conclusions.
\end{abstract}

KEY WORDS: Biodiversity $\cdot$ Species richness $\cdot$ Rarity $\cdot$ Average taxonomic distinctness $\cdot$ Latitudinal and longitudinal patterns $\cdot$ Hotspots

\section{INTRODUCTION}

While biodiversity characterization traditionally focuses on species richness $(S)$, marine ecologists are now examining biodiversity patterns determined from a broader repertoire of metrics. Amongst these are average taxonomic distinctness $\left(\Delta^{+}\right.$, the average degree to which species are related to each other; Clarke \& Warwick 1998, Warwick \& Clarke 1998), endemism or other measures of 'uniqueness' such as rarity $(R)$ (Price et al. 2002), and sometimes also $\beta$-diversity, i.e. species turnover along some gradient (e.g. Izsak \& Price 2001, Price 2002, Bolton et al. 2004).
Observed biodiversity patterns can greatly depend on the choice of metric (Price et al. 1999, Price 2002), such that a given depth-zone, or geographic area, can paradoxically be both a hotspot and coldspot of biodiversity. For example, the Arabian/Persian Gulf is impoverished in terms of species richness of many groups (Price 1982, Price et al. 2002, Sheppard et al. 1992), yet it may not be the coldspot generally acclaimed if the selection of biodiversity measures is expanded (Price 2002, Price \& Izsak 2005).

It is also clear that relationships between different metrics are rather complex. Ellingsen et al. (2005) show that benthos of the Norwegian continental shelf 
displays dissimilar patterns of $\Delta^{+}$and $S$, and that molluscs show different patterns of $\Delta^{+}$to annelids and crustaceans. Hence, one phylum is not necessarily a reliable surrogate for another or for overall biodiversity, nor are patterns necessarily the same for different metrics. Similar findings emerged from a recent study of freshwater invertebrates, microflora (diatoms), bryophytes and fish (Heino et al. 2005). Apart from this and an earlier study of diatoms (Izsak et al. 2002), we are unaware of studies that have comprehensively examined relationships between $S$ and $\Delta^{+}$in aquatic flora.

In this study, we analyze a comprehensive benthic algal dataset (species presence/absence) for the Indian Ocean region. This published dataset (Silva et al. 1996) comprises all published records for macroalgae in the region up to that date. Although studies since 1996 have added species to some areas, especially in the Arabian Sea, the overall effect on the dataset is generally minor, given the extensive records in Silva et al. (1996; bibliography 222 pages). The Indian Ocean makes up the greater part of the Indo-West Pacific, which is recognised by seaweed biologists as the largest and most diverse marine biogeographic region on earth (van den Hoek 1984, Lüning 1990). This dataset is obviously a significant resource for analysis of biogeographic patterns, and has recently been used to investigate the use of a new tripartite biographic index (Schils in press). The main aims of the current study were to: (1) determine relationships between $S, R$ and $\Delta^{+}$- measures that vary in robustness to different sampling approaches-and whether one phylum/higher division can act as a surrogate for another in marine flora; (2) identify Indian Ocean sites of highest and lowest macroalgal diversity, based upon an expanded view of biodiversity; and (3) examine latitudinal (and longitudinal) diversity patterns, in light of previous seaweed studies that report a lack of a tropical species richness high (Silva 1992, Bolton 1994, Gray 1997, Santelices et al. in press).

\section{METHODS}

Study area and sites. The sites generally match those of Silva et al. (1996), despite occasional inconsistencies between geographical definition of the Indian Ocean and known biogeographic patterns (Bolton et al. 2004). Following Silva et al. (1996), Amsterdam and St Paul islands in the southern Indian Ocean are included, but the Kerguelen and other sub-Antarctic islands are excluded, as are the Red Sea and southern coast of Australia. Some site designations (e.g. 'Indian Ocean', 'western and eastern Indian Ocean', 'East Indies') are too general to permit spatial analysis and are excluded. Following these and other transformations (Vincent 2000), our study area comprised 66 sites (Fig. 1). The latitude and longitude for each site were taken from an atlas. For large sites, the mid-point of the coastline or island was used.

Following the above transformations, and exclusion of subspecific taxa, the total count of benthic algae was 2894 species: Xanthophyta, 10 species; Chlorophyta, 476 species; Phaeophyta, 455 species; Rhodophyta, 1680 species; Cyanophyta, 273 species. Although the latter are bacteria, i.e. prokaryotes (more usually currently known as Cyanobacteria), we include them in line with Silva et al. (1996) and some other marine botanical literature (e.g. Basson 1979). 'Algae' and 'seaweed' are ecological and not taxonomic terms (Ragan 1998). It is also noted that Cyanophyta comprise only a small proportion $(<10 \%)$ of the total number of species. The data matrix used for biodiversity analysis was 66 sites $\times 2894$ species.

Species richness. Because sample size/area strongly influences species richness (Warwick \& Clarke 1995, Clarke \& Warwick 1998), values were transformed to adjust for disparities in coastline length (50 to $10475 \mathrm{~km}$ ). Plots of log coastline length against log species richness (Fig. 2) are more strongly correlated $(\mathrm{r}=0.45, \mathrm{p} \leq 0.01)$ than plots of linear values $(\mathrm{r}=0.38$, $\mathrm{p} \leq 0.01$ ). This log-log plot is equivalent to similar very well established relationships between terrestrial spe-

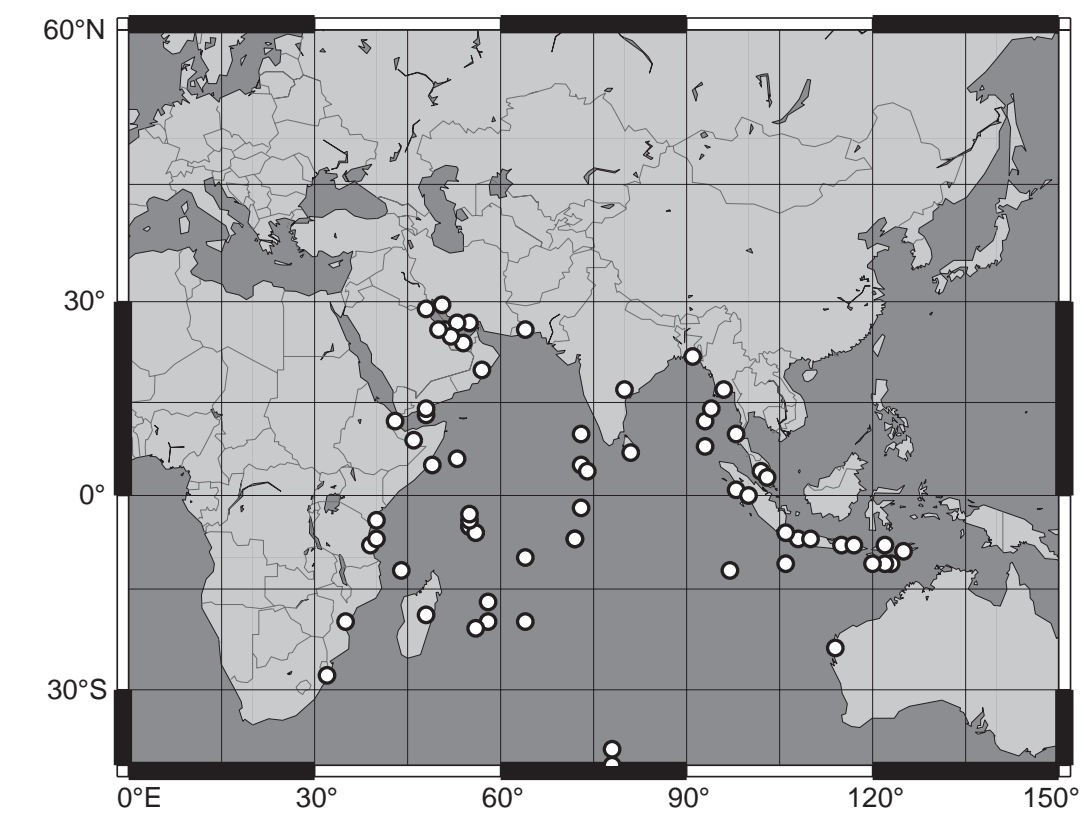

Fig. 1. Map showing 66 sampling locations in the Indian Ocean (see Table 1 for names and abbreviations of locations) 
cies richness and area (Rosenzweig 1995, Santelices et al. in press). Species richness $(S)$ is therefore expressed as log species numbers/log coast length, although other non-linear species/area relationships are also known (He \& Legendre 1996, Price et al. 1999).

Rarity. $R$ was taken as a function of range size, not abundance (see Williams et al. 1996). It was calculated for all the species in a site as the sum of each species' inverse number of site/area ('grid/cell') records (see Williams et al. 1996):

$$
\begin{gathered}
\text { Rarity score }=\sum\left(1 / C_{i}\right) \\
\left\{i: C_{i} \neq 0,1 \leq i \leq n\right\}
\end{gathered}
$$

where $c_{i}$ is the number of sites/areas occupied by species $i$. We measured range size within the context of the Indian Ocean, following the approach of Williams et al. (1996) whose measurement (birds) was confined to Britain. However, in our study the 66 sites were discrete, of unequal size and not necessarily contiguous (Fig. 1) in contrast to use of grid cells used in other studies (e.g. Williams et al. 1996). Importantly, these measures of rarity are much less scale-dependent than endemism, even when the latter is expressed as percentage endemism for a region (Price et al. 2002). The theoretical range in possible values of $R$ (all phyla/higher designations combined) for a site is between 1/66 (only 1 species at a site, but represented at all sites) and 2893 (2893 species occurring at a particular site but at no others, and the single remaining species representing the entire complement at each of the remaining 65 sites).

Average taxonomic distinctness. The $\Delta^{+}$index which shows the average path length between any 2 randomly selected species) was developed by Clarke \& Warwick (1998). It reflects the convergence of 2 quan-

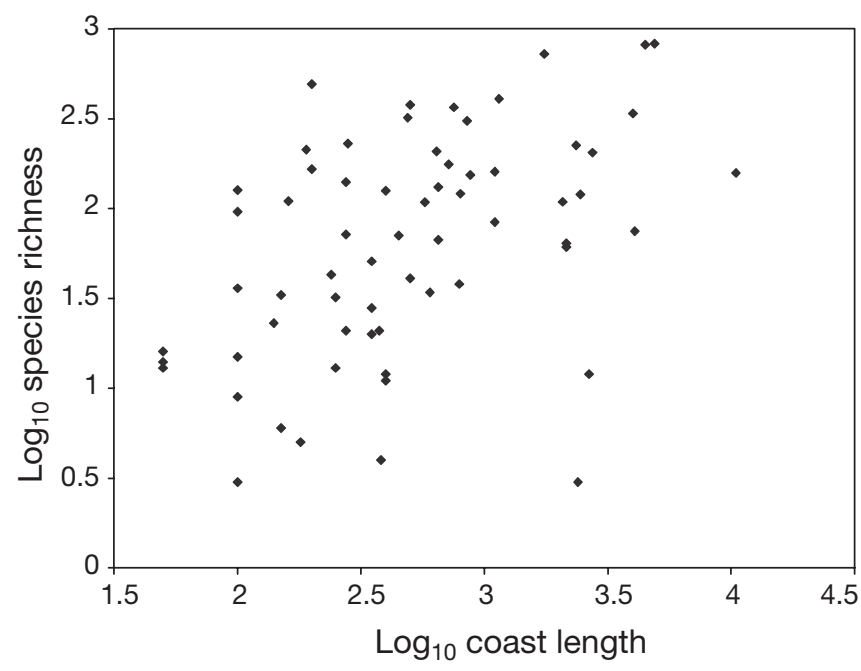

Fig. 2. Relationship between $\log _{10}$ species richness (all phyla/ divisions) and $\log _{10}$ coastline length titative measures, taxonomic diversity $(\Delta)$ and taxonomic distinctness $\left(\Delta^{*}\right)$, formulated earlier (Warwick \& Clarke 1995) when the data consisted of presence/ absence information. $\Delta$ is the average path length between any 2 randomly selected organisms, as is $\Delta^{*}$, assuming they are of different species. Unlike conventional 'species' indices, such as Simpson's and Shannon-Wiener, $\Delta^{+}$(and other 'taxonomic' indices) takes into account the taxonomic level at which any 2 species are related. Hence, their identity matters. A simple linear weighting factor $\left(\mathrm{w}_{i j}\right)$ is applied, such that $w=1$ (for species $i$ and $j$ within the same genus), $w=2$ (for species within different genera but the same order), $w=3$ (for species within different families but the same class)...etc.

The choice of path lengths is somewhat arbitrary. We have used essentially constant incremental path lengths $\left(1,2,3\right.$ etc.) throughout this study for $\Delta^{+}$following the robustness of relative values of $\Delta^{+}$to variation in the definition of path length (Clarke \& Warwick 1999, see also Ellingsen et al. 2005). Weightings used for taxonomic levels within a 'class', i.e. highest division or phylum, were based on the classification used by Silva et al. (1996) as follows:

$$
\begin{array}{ccccc}
\text { Species } & \rightarrow \text { Genus } \rightarrow \text { Family } & \rightarrow \text { Order } \rightarrow \text { 'Subclass' } \\
1 & 2 & 3 & 4 & 5 \text { (Rhodophyta only) }
\end{array}
$$

For analysis of $\Delta^{+}$for all algal phyla/higher divisions (collectively), weightings of species in different divisions reflect the phylogenetic classification of Tudge (2000), utilising molecular techniques: Chlorophyta, 6; Phaeophyta and Xanthophyta, 7; Rhodophyta, 8; Cyanophyta, 10. Since there is another taxonomic level between the Rhodophyta and Cyanophyta, comprising Eukarya and Archaea but unrepresented by algae, there is no weighting factor of ' 9 '. Where 2 phyla/higher divisions were compared as part of the calculation, the mean of the 2 weightings was used. There is mixed opinion on the validity of computing $\Delta^{+}$for different groups combined (reviewed in Ellingsen et al. 2005).

$\Delta^{+}$is the average (weighted) path length, i.e. between any 2 species in a sample/assemblage and, when used with presence-absence data, may be defined as follows:

$$
\Delta^{+}=\frac{\sum_{i} \sum_{j>i} w_{i j}}{N(N-1) / 2}
$$

where the summations are over the number of species present $(\mathrm{N})$, and $W_{i j}$ is the 'distinctness weight' given to the path linking species $i$ and $j$ in the hierarchical classification.

Statistical analysis. The degree of association between variables was calculated using Pearson's corre- 
lation coefficient (r) for parametric data when normally distributed. Spearman's rank correlation coefficient $\left(\mathrm{r}_{\mathrm{s}}\right)$ was used for non-normal data, and for correlations involving $\Delta^{+}$, since values computed from a similarity matrix may not be completely independent of one another (see Izsak \& Price 2001).

\section{RESULTS}

\section{Hotspots and coldspots of marine algal biodiversity}

Values of $S, R$ and $\Delta^{+}$for each site are shown in Table 1. Ranked values (1 to 66) for the sites are also shown according to the 3 different measures, all of which are strongly positively inter-correlated ( $p \leq 0.01)$. For each pair of measures, $\mathrm{r}_{\mathrm{S}}$ values were: $0.74(S$ vs. $R$ ), $0.45\left(S\right.$ vs. $\left.\Delta^{+}\right)$and $0.51\left(R\right.$ vs. $\left.\Delta^{+}\right)$. These results suggest that, in general, a biodiversity hotspot (or coldspot) is so irrespective of which of the 3 measures is used.

An overall measure of biodiversity can be determined by summing the rankings for $S, R$ and $\Delta^{+}$ (Table 1). These aggregate values, when ranked, revealed Mauritius, India and Aldabra as the sites of highest diversity. Conversely, Indonesia (Nias Island), Maldives (Male Atoll) and the Gulf of Aden emerged as the sites of lowest diversity.

\section{Latitudinal and longitudinal patterns in biodiversity}

$S$, computed for algae as a whole, and for each higher division/phylum, was not significantly correlated with latitude (Table 2). Significant negative correlation with longitude was evident for algae as a whole as well as for Cyanophyta, Rhodophyta and Chlorophyta (Table 2). This corresponds with generally higher values of $S$ in regions within 30 to $80^{\circ} \mathrm{E}$, and with lower values further east within 80 to $120^{\circ} \mathrm{E}$ (data not shown). $R$ showed no significant correlation with latitude, and only Cyanophyta showed significant correlation (negative) with longitude (Table 2). $\Delta^{+}$ showed significant correlation (negative) with latitude only for Phaeophyta, equating to an increase towards temperate waters in the southern hemisphere (Table 2: footnote) while for longitude no significant association was evident (Table 2).

\section{DISCUSSION}

Our study utilizes low-resolution (species presence/ absence) data at sites of variable size and which are often widely separated. It is noted that sites do not always correspond with known biogeographical regions; for example, India is represented by only 1 site, even though its western and eastern coasts have different biological compositions (Clark \& Rowe 1971). A more extreme instance is the Red Sea: this is a large body of water of exceptionally high biodiversity (Sheppard et al. 1992, Price \& Izsak 2005), yet it is unrepresented (see 'Methods'). Conversely there can be bias towards some small regions. For example, the Persian/ Arabian Gulf comprises a regional site, as well as separate sub-regional sites (Bahrain, Iran, Iraq, Kuwait, Qatar, Saudi Arabia). For assessment over large oceanic areas, like the Indian Ocean, site designations are seldom ideal, particularly if existing datasets (rather than field data, for which there is more control over study sites) are analyzed. Related to this, our data originated solely from Silva et al. (1996), and we did not utilize records from more recent studies. There have been many studies that have added to species and distribution records for various parts of the Indian Ocean since 1996 but, with exceptions (e.g. Yemen, Kenya, Tanzania, Oman), in relatively small numbers compared to the wealth of records in Silva et al. (1996). A further point is that not all sites have been sampled equally thoroughly. While there might be merit in selecting and analyzing only well-investigated sites, our preferred approach was to analyze all the data, albeit of variable quality, rather than a more limited dataset. However, we acknowledge the limitations imposed by this. As indicated, there is also variation in size of the sites, which we controlled for using 'log/log' transformations in the case of $S$ (see 'Methods'). Adjusting for size disparities in data used for $R$, however, would be less straightforward. Hence some values could potentially be biased, particularly since sites are not distributed evenly. While these constraints and the (necessarily) low resolution data utilized permitted only broadscale biogeographic analysis, we do not see this as seriously undermining evaluation of different biodiversity measures.

Unlike $\Delta^{+}, S$ is highly sensitive to uneven sampling areas and effort, even though our computations of $S$ attempted to standardize for area disparities (see 'Methods'); $R$ shares these properties of $S$ to some extent, but (unlike endemism) it is relatively unaffected by spatial scale (Price et al. 2002). Hence, $\Delta^{+}$is more robust to disparities in sampling (and taxonomic) rigour than most 'species' measures (Warwick \& Clarke 1998, Izsak \& Price 2001) such as $S$ and hence $R$. The highly significant positive correlation between all 3 biodiversity metrics is therefore unexpected, particularly since $\Delta^{+}$is conceptually unrelated to $S$ and hence also $R$.

Combining $S, R$ and $\Delta^{+}$to determine overall rank order, Mauritius, India and Aldabra emerge as the greatest biodiversity hotspots. India may be a hotspot 
Table 1. Algal biodiversity (all phyla/higher divisions) hotspots and coldspots across the Indian Ocean, based on species richness $(S)$, range rarity $(R)$ and average taxonomic distinctness $\left(\Delta^{+}\right)$

\begin{tabular}{|c|c|c|c|c|c|c|c|c|}
\hline \multirow{2}{*}{ Locality } & \multirow{2}{*}{ Code } & & \multirow{2}{*}{$\begin{array}{l}S-\text { Ranked } \\
\text { value } \\
(1=\text { highest })\end{array}$} & & \multirow{2}{*}{$\begin{array}{l}R- \\
\text { Ranked } \\
\text { value } \\
(1=\text { highest })\end{array}$} & \multirow{2}{*}{$\overline{\text { Value }}$} & \multirow{2}{*}{$\begin{array}{c}\left(\Delta^{+}\right)- \\
\text {Ranked } \\
\text { value } \\
(1=\text { highest })\end{array}$} & \multirow{2}{*}{$\begin{array}{c}\text { Overall } \\
\text { ranked values } \\
\text { (from sum } \\
\text { of } 3 \text { ranks) }\end{array}$} \\
\hline & & Value & & Value & & & & \\
\hline Abu Dhabi & $\mathrm{AD}$ & 0.36 & 61 & 3.57 & 54 & 5.8 & 46 & 58 \\
\hline Aldabra Islands & $\mathrm{AL}$ & 0.96 & 6 & 36.98 & 20 & 6.6 & 7 & 3 \\
\hline Amirante Islands & $\mathrm{AI}$ & 0.58 & 45 & 11.72 & 39 & 5.47 & 56 & 50 \\
\hline Amsterdam Island & AMI & 0.54 & 50 & 9.3 & 42 & 5.18 & 59 & 55 \\
\hline Andaman Islands & ANI & 0.74 & 23 & 30.63 & 21 & 5.97 & 34 & 23 \\
\hline Australia & $\mathrm{OZ}$ & 0.8 & 17 & 545.73 & 1 & 5.92 & 40 & 20 \\
\hline Bahrain & BAH & 0.93 & 9 & 16.44 & 33 & 6.68 & 4 & 12 \\
\hline Bangladesh & BAN & 0.79 & 19 & 48.65 & 14 & 6.7 & 3 & 4 \\
\hline Cargados Carajos & $\mathrm{CAC}$ & 0.7 & 30 & 9.23 & 43 & 4.87 & 62 & 47 \\
\hline Chagos Archipelago & CA & 0.55 & 47 & 6.21 & 47 & 5.23 & 57 & 56 \\
\hline $\begin{array}{l}\text { Chagos Archipelago } \\
\text { (Egmont Atoll) }\end{array}$ & $\mathrm{CAE}$ & 0.78 & 20 & 4.66 & 50 & 6.4 & 11 & 24 \\
\hline Christmas Island & XMA & 0.63 & 38 & 4.69 & 49 & 6.05 & 27 & 39 \\
\hline Cocos (Keeling) Islands & $\mathrm{COK}$ & 0.36 & 60 & 0.64 & 64 & 5.8 & 47 & 61 \\
\hline Comoro Islands & COM & 0.67 & 35 & 12.86 & 36 & 5.78 & 48 & 42 \\
\hline Diego Garcia Atoll & DGA & 0.99 & 4 & 15.85 & 34 & 6.22 & 14 & 17 \\
\hline Djibouti & DJI & 0.7 & 31 & 20.2 & 27 & 6.75 & 2 & 21 \\
\hline Gulf of Aden & GOA & 0.14 & 66 & 0.48 & 65 & 1 & 66 & 66 \\
\hline India & IND & 0.79 & 18 & 347.34 & 3 & 6.54 & 8 & 2 \\
\hline Indonesia & I & 0.55 & 48 & 39.63 & 17 & 6.1 & 19 & 26 \\
\hline Indonesia (Bali) & IB & 0.41 & 58 & 3.37 & 56 & 4.89 & 61 & 62 \\
\hline Indonesia (Flores) & IF & 0.55 & 49 & 12.12 & 37 & 6.27 & 13 & 34 \\
\hline Indonesia (Java) & IJ & 0.61 & 42 & 38.35 & 19 & 5.94 & 38 & 35 \\
\hline Indonesia (Lombok) & IL & 0.51 & 55 & 7.75 & 45 & 6.06 & 24 & 43 \\
\hline Indonesia (Nias Island) & IN & 0.23 & 65 & 3.2 & 57 & 3.67 & 63 & 64 \\
\hline Indonesia (Rotti) & IR & 0.46 & 57 & 3.7 & 52 & 5.85 & 44 & 57 \\
\hline Indonesia (Sawu) & ISA & 0.31 & 63 & 2.3 & 60 & 6.5 & 9 & 45 \\
\hline Indonesia (Sumatra) & ISU & 0.52 & 53 & 18.55 & 29 & 6.05 & 29 & 38 \\
\hline Indonesia (Sumba) & ISM & 0.6 & 43 & 7.37 & 46 & 5.84 & 45 & 46 \\
\hline Indonesia (Sunda Strait) & ISN & 0.4 & 59 & 2.18 & 61 & 3.25 & 64 & 63 \\
\hline Indonesia (Timor) & IT & 0.63 & 39 & 24.74 & 24 & 6.09 & 21 & 27 \\
\hline Iran & IRN & 0.61 & 41 & 16.87 & 32 & 6.15 & 17 & 33 \\
\hline Iraq & IRQ & 0.67 & 33 & 2.58 & 59 & 5.53 & 54 & 52 \\
\hline Kenya & KEN & 0.95 & 7 & 63.32 & 10 & 6.06 & 26 & 11 \\
\hline Kuwait & KUW & 0.88 & 12 & 23.49 & 25 & 6.66 & 5 & 9 \\
\hline Laccadive Islands & LAC & 0.75 & 22 & 15.67 & 35 & 6 & 31 & 30 \\
\hline Madagascar & $\mathrm{MA}$ & 0.7 & 28 & 94.82 & 7 & 6.2 & 15 & 14 \\
\hline Malaysia & MLY & 0.72 & 26 & 18.22 & 30 & 5.89 & 43 & 36 \\
\hline Maldives & MV & 0.83 & 15 & 54.49 & 12 & 6.33 & 12 & 6 \\
\hline Maldives (Addu Atoll) & MVA & 0.66 & 36 & 3.4 & 55 & 5.22 & 58 & 54 \\
\hline Maldives (Male Atoll) & MVM & 0.24 & 64 & 0.28 & 66 & 1.67 & 65 & 65 \\
\hline Mauritius & MU & 1.17 & 1 & 148.45 & 4 & 6.1 & 20 & 1 \\
\hline Mozambique & MOZ & 0.7 & 29 & 57.87 & 11 & 6.41 & 10 & 15 \\
\hline Myanmar & MY & 0.54 & 52 & 19.92 & 28 & 6.65 & 6 & 28 \\
\hline Myanmar (Coco Group) & MYC & 0.71 & 27 & 1.95 & 62 & 6.17 & 16 & 37 \\
\hline Nicobar Islands & NIC & 0.81 & 16 & 17.66 & 31 & 5.89 & 42 & 31 \\
\hline Oman & $\mathrm{O}$ & 0.54 & 51 & 9.91 & 40 & 5.94 & 37 & 44 \\
\hline Pakistan & PAK & 0.85 & 14 & 99.09 & 6 & 6.05 & 28 & 13 \\
\hline Persian Gulf & PEG & 0.32 & 62 & 3.62 & 53 & 6 & 30 & 51 \\
\hline Qatar & QTR & 0.51 & 54 & 2.65 & 58 & 5.48 & 55 & 59 \\
\hline Reunion & REU & 0.97 & 5 & 45.14 & 15 & 6.09 & 22 & 10 \\
\hline Rodriguez Island & ROD & 0.69 & 32 & 5.37 & 48 & 5.95 & 36 & 40 \\
\hline Saudi Arabia & SAU & 0.74 & 24 & 22.92 & 26 & 6.76 & 1 & 16 \\
\hline Saya de Malha Bank & SAY & 0.57 & 46 & 9.48 & 41 & 5.73 & 49 & 49 \\
\hline Seychelles & SY & 0.93 & 8 & 71.02 & 8 & 6.08 & 23 & 7 \\
\hline Seychelles (Coetivy Reef) & SYC & 0.59 & 44 & 4.58 & 51 & 5.6 & 52 & 53 \\
\hline Seychelles (Mahe Island) & SYM & 1.05 & 2 & 30.06 & 22 & 5.58 & 53 & 22 \\
\hline Seychelles (Praslin Island) & SYP & 0.48 & 56 & 1.32 & 63 & 5.64 & 51 & 60 \\
\hline Singapore & SIN & 1.02 & 3 & 51.4 & 13 & 6.06 & 25 & 8 \\
\hline Somalia & SOM & 0.67 & 34 & 40.59 & 16 & 6 & 32 & 25 \\
\hline South Africa & $\mathrm{SA}$ & 0.88 & 11 & 396.72 & 2 & 5.91 & 41 & 18 \\
\hline Sri Lanka & SRI & 0.85 & 13 & 116.46 & 5 & 6.12 & 18 & 5 \\
\hline St. Paul Island & STP & 0.76 & 21 & 39.63 & 18 & 5.7 & 50 & 32 \\
\hline Tanzania & $\mathrm{TZ}$ & 0.89 & 10 & 68.32 & 9 & 5.97 & 35 & 19 \\
\hline Tanzania (Zanzibar) & $\mathrm{TZZ}$ & 0.63 & 40 & 8.21 & 44 & 5.99 & 33 & 41 \\
\hline Thailand & THA & 0.65 & 37 & 11.76 & 38 & 5.12 & 60 & 48 \\
\hline Yemen & YEM & 0.73 & 25 & 27.35 & 23 & 5.93 & 39 & 29 \\
\hline
\end{tabular}


Table 2. Latitudinal and longitudinal patterns of benthic macroalgal biodiversity for Indian Ocean algae based on species richness $(S)$, rarity $(R)$ and average taxonomic distinctness $\left(\Delta^{+}\right)$. Values are Spearman's rank correlation $\left(\mathrm{r}_{\mathrm{S}}\right)$ unless otherwise indicated. Negative correlation corresponds to a biodiversity increase towards higher latitudes in the southern hemisphere, as values on the $x$-axis included southern latitudes (negative values) and northern latitudes (positive values). The absence of other latitudinal patterns is evident from the table and from plots of data for $\mathrm{N}$ and $\mathrm{S}$ hemispheres separately. ${ }^{* *}: \mathrm{p} \leq 0.01,{ }^{*}: \mathrm{p} \leq 0.05$; otherwise correlations not significant; see also 'Methods'

\begin{tabular}{|lccr|}
\hline & $S$ & $R$ & \multicolumn{1}{c|}{$\Delta^{+}$} \\
\hline Latitudinal pattern & & & \\
All groups & $-0.067^{\mathrm{a}}$ & -0.081 & 0.197 \\
Cyanophyta & $0.194^{\mathrm{a}}$ & 0.103 & 0.062 \\
Rhodophyta & $-0.173^{\mathrm{a}}$ & -0.201 & -0.021 \\
Chlorophyta & $0.0546^{\mathrm{a}}$ & -0.069 & -0.065 \\
Phaeophyta & $0.034^{\mathrm{a}}$ & -0.012 & $-0.273^{*}$ \\
Longitudinal pattern & & & \\
All groups & $-0.319^{* *}$ & -0.179 & -0.081 \\
Cyanophyta & $-0.544^{\mathrm{a}}$,** $^{*}$ & $-0.343^{*}$ & -0.006 \\
Rhodophyta & $-0.272^{*}$ & -0.140 & 0.113 \\
Chlorophyta & $-0.402^{* *}$ & -0.074 & 0.234 \\
Phaeophyta & -0.191 & -0.062 & -0.005 \\
aCorrelation coefficients $(\mathrm{r})$ & & \\
\hline
\end{tabular}

partly because it spans a large latitudinal and longitudinal range and has different marine floras. In seeming contrast, the world's richest seaweed areas are reported for temperate regions (Pacific northwest coast of the USA, Japan, southern Australia and Mediterranean; Silva 1992, Bolton 1994); South Africa, which contains elements of temperate, tropical and subtropical floras, also has an extremely rich seaweed flora with more than 800 species (Bolton \& Stegenga 2002, Bolton et al. 2004, J. J. Bolton unpubl. data). Silva et al. (1996) and thus our analysis includes only species from the Indian Ocean coast of South Africa. However, most of our study sites are tropical, and a few subtropical, with only 2 sites at latitudes (mid-point) greater than $35^{\circ}$. This makes temperate/tropical comparison difficult, especially since southern Australia is not included. Our biodiversity analyses rank the Indian Ocean coast of South Africa 18th out of the 66 sites in terms of $S, R$ and $\Delta^{+}$combined, though second according to $R$ (Table 1) and third based on unadjusted species counts ( 729 species; i.e. raw data rather than $S$ : $\log$ species divided by coastline length; data not shown).

All latitudinal associations with $S$ and $R$ were weak, for $\mathrm{N}$ and $\mathrm{S}$ hemispheres combined (Table 2) and from visual inspection of data for each hemisphere separately. This observation supports the overall lack of a tropical macroalgal species richness high and absence of clear relationship with latitude (Silva 1992, Bolton 1994, Gray 1997, Santelices et al. in press). The 'pseudo-high latitude' effect (Sheppard \& Salm 1988) might be a partial explanation. Due to cool upwelling, sea temperatures in tropical waters can actually become cooler than at higher latitudes, obscuring any biophysical differences along a latitudinal gradient. However, the effect is predominant in upwelling areas, for example off the coast of Oman in the Arabian Sea (i.e. locally), rather than at the larger scale of the Indian Ocean region. We also note that values of Rhodophyta (red algae) to Phaeophyta (brown algae), i.e. the R/P ratio, are maximal in low latitudes (data not shown). The relationship is most marked in the northern hemisphere $(r=-0.327, p \leq 0.05)$. Again, this accords with the data of Santelices et al. (in press). This suggests that Phaeophyta species are relatively more abundant at higher latitudes (i.e. less abundant at lower latitudes), even though the range of latitudinal values in our study was rather limited: $30^{\circ} \mathrm{N}$ to $40^{\circ} \mathrm{S}$. $\Delta^{+}$showed a significant increase towards higher latitudes in the southern hemisphere (see Table 2), but only for Phaeophyta.

While longitudinal biodiversity patterns were more prevalent, correlations (negative) were significant only for $S$ (all groups combined and certain groups) and $R$ (Cyanophyta only); correlation between longitude and $\Delta^{+}$was not significant. This suggests that the western Indian Ocean sites may be, in some cases - perhaps surprisingly - more diverse than eastern Indian Ocean sites. This finding cannot be compared with previous literature (e.g. Silva 1992, Bolton 1994), as previous authors (excepting Santelices et al. in press) have made no attempt to relate diversity measures to coastline length.

In conclusion $S, R$ and $\Delta^{+}$showed strong concurrence in terms of ranking sites as biodiversity hotspots and coldspots. The virtual absence of significant latitudinal correlation for all 3 metrics, in contrast to the variable patterns observed with longitude, suggests that relationships between different biodiversity measures in marine floras may not be straightforward. This accords with recent observations obtained mainly from aquatic fauna datasets (e.g. Ellingsen et al. 2005, Heino et al. 2005). In particular, one taxonomic category may not be a reliable surrogate for biodiversity in another, nor the group as a whole. Similarly, patterns for different biodiversity metrics may not always mirror each other; however, interestingly, good concordance between various 'species' and 'taxonomic' measures may occur, as in the case of reef flat corals in Thailand (Brown et al. 2002). In general, relationships between different metrics are likely to depend on both the group(s) selected and the particular environmental or geographical factor(s) examined.

We based our study on analysis of low resolution (presence/absence) data (Silva et al. 1996) collected 
from sites of variable size and sampled unevenly. Trade-offs between data resolution and coverage/ extent of an assessment are inevitable in choices between fine-scale/focused vs. broad-scale/extensive studies (Wiens 1989, Price et al. 1999). We addressed these issues, but acknowledged the possibility that some patterns observed could prove to be artefacts, pending analysis of data from recent and ongoing studies. However, we do not expect this to significantly affect the conclusions.

Acknowledgements. We thank Sam Mason for assistance with Excel and Access databases and Laura Green and Calvin Dytham for statistical advice.

\section{LITERATURE CITED}

Basson PW (1979) Marine algae of the Arabian Gulf coast of Saudi Arabia (first half). Bot Mar 22:47-64

Bolton JJ (1994) Global seaweed diversity: patterns and anomalies. Bot Mar 37:241-245

Bolton JJ, Stegenga H (2002) Seaweed biodiversity in South Africa. S Afr J Mar Sci 24:9-18

Bolton JJ, Leliaert F, De Clerck O, Anderson RJ, Stegenga H, Engledow HE, Coppejans E (2004) Where is the western limit of the tropical Indian Ocean seaweed flora? An analysis of intertidal seaweed biogeography on the east coast of South Africa. Mar Biol 144:51-59

Brown BE, Clarke KR, Warwick RM (2002) Serial patterns of biodiversity change in corals across shallow reef flats in Ko Phuket, Thailand, due to the effects of local (sedimentation) and regional (climatic) perturbations. Mar Biol 141:24-29

Clark AM, Rowe FEW (1971) Monograph of shallow-water Indo-West Pacific echinoderms. British Museum (Natural History), London

Clarke KR, Warwick RM (1998) A taxonomic distinctness index and its statistical properties. J Appl Ecol 35:423-53

Clarke KR, Warwick RM (1999) The taxonomic distinctness measure of biodiversity: weighting of step lengths between hierarchical levels. Mar Ecol Prog Ser 184:21-29

Ellingsen KE, Clarke KR, Somerfield PJ, Warwick RM (2005) Taxonomic distinctness as a measure of diversity applied over a large scale: the benthos of the Norwegian continental shelf. J Anim Ecol 74:1069-1079

Gray JS (1997) Marine biodiversity: patterns, threats and conservation needs. Biodivers Conserv 6:153-175

He F, Legendre P (1996) On species area relationships. Am Nat 148:719-737

Heino J, Soininen J, Lappalainen J, Virtanen R (2005) The relationship between species richness and taxonomic distinctness in freshwater organisms. Limnol Oceanogr 50: 978-986

Izsak C, Price ARG (2001) Measuring $\beta$-diversity using a taxonomic similarity index, and its relation to spatial scale. Mar Ecol Prog Ser 215:69-77

Izsak C, Price ARG, Hardy JT, Basson PW (2002) Biodiversity of periphyton (diatoms) and echinoderms around a re- finery effluent, and possible associations with stability. Aquat Ecosyst Health Manage 5:233-242

Lüning K (1990) Seaweeds: their environment, biogeography and ecophysiology. Wiley Interscience, New York

Price ARG (1982) Echinoderms of Saudi Arabia: comparison between echinoderm faunas of Arabian Gulf, SE Arabia, Red Sea and Gulfs of Aqaba and Suez. Fauna Saudi Arabia 4:3-21

Price ARG (2002) Simultaneous 'hotspots' and 'coldspots' of marine biodiversity and implications for global conservation. Mar Ecol Prog Ser 241:23-27

Price ARG, Izsak C (2005) Is the Arabian Gulf really such a lowspot of biodiversity?: scaling effects and management implications. Aquat Ecosyst Health Manage 8:363-366

Price ARG, Keeling MJ, O'Callaghan CJ (1999) Ocean-scale patterns of 'biodiversity' of Atlantic asteroids determined from taxonomic distinctness and other measures. Biol J Linn Soc 66:187-203

Price ARG, Jones DA, Krupp F (2002) Biodiversity. In: Khan NY, Munawar M, Price ARG (eds) The Gulf ecosystem health and sustainability. Backhuys, AH Leiden, p 105-123

Ragan MA (1998) On the delineation and higher-level classification of algae. Eur J Phycol 33:1-16

Rosenzweig ML (1995) Species diversity in space and time. Cambridge University Press, Cambridge

Santelices B, Bolton JJ, Meneses I (in press) Marine algal communities. In: Whitman JD, Roy K (eds) Marine macroecology. University of Chicago Press, Chicago

Schils $\mathrm{T}$ (in press) The tripartite biogeographic index, a tool for quantifying macroalgal distribution patterns in the Indian Ocean. J Biogeogr

Sheppard CRC, Salm RV (1988) Reef and coral communities of Oman, with a description of a new coral species (Order Scleractinia, genus Acanthastrea). J Nat Hist 22:263-279

Sheppard CRC, Price ARG, Roberts CM (1992) Marine Ecology of the Arabian region: patterns and processes in extreme tropical environments. Academic Press, London

Silva PC (1992) Geographic patterns of diversity in benthic marine algae. Pac Sci 46:429-437

Silva PC, Basson PW, Moe RL (1996) Catalogue of the benthic marine algae of the Indian Ocean. University of California Press, Berkeley

Tudge C (2000) The variety of life: a survey and a celebration of all the creatures that have ever lived. Oxford University Press, Oxford

van den Hoek C (1984) World-wide longitudinal seaweed distribution patterns and their possible causes, as illustrated by the distribution of rhodophytan genera. Helgol Meeresunters 38:227-257

Vincent LPA (2000) Analysis of biodiversity patterns of Indian Ocean algae and their implications to governance. MSc thesis, University of Warwick

Warwick RM, Clarke KR (1995) New 'biodiversity' index measures reveal a decrease in taxonomic distinctness with increasing stress. Mar Ecol Prog Ser 129:301-305

Warwick RM, Clarke KR (1998) Taxonomic distinctness and environmental assessment. J Appl Ecol 35:532-543

Wiens JA (1989) Spatial scaling in ecology. Funct Ecol 3: 385-397

Williams P, Gibbons D, Margules C, Rebelo A, Humphries C, Pressey R (1996) A comparison of richness hotspots, rarity hotspots, and complementary areas for conserving diversity of British birds. Conserv Biol 10:155-174 